\title{
Comparison of fentanyl with dexmedetomidine for smooth extubation: A clinical study
}

\author{
Vibhor Rai ${ }^{1 *}$, Mubashar UI Islam², Sweety Malik ${ }^{3}$ \\ ${ }^{1-3}$ Assistant Professor, ${ }^{1,2}$ Dept. of Anaesthesia \& Critical Care, ${ }^{3}$ Dept. of Gynaecology \& Obstetrics, Saraswathi Institute of Medical \\ Sciences, Hapur, Uttar Pradesh, India \\ *Corresponding Author: Vibhor Rai \\ Email: dr.vibhor.rx@gmail.com
}

\begin{abstract}
Introduction: In general anaesthesia, commonly due to sympathetic responses patients develop tachycardia and increased secretion and bronchospasm while extubation. Fentanyl and dexmedetomidine are well known to suppress airway reflexes during airway procedures.

Aim: This study is design to compare the effects of fentanyl $1 \mu \mathrm{g} / \mathrm{kg}$ and dexmedetomidine $0.75 \mu \mathrm{g} / \mathrm{kg}$ in attenuating airway and circulatory reflexes during emergence and extubation of the endotracheal tube.

Materials and Methods: This double-blind, randomized, controlled study was done in fifty patients undergoing surgery under general anaesthesia belonging to (ASA) physical status 1 or 2 . Study drugs dexmedetomidine (Group D) \& Fentanyl (Group F) was given 15 min before the end of surgery as an infusion and over $15 \mathrm{~min}$ post extubation. Hemodynamic parameters and patient response for laryngoscopy like respiratory pattern, airway status and oral suctioning and during extubation were graded.

Discussion: Aside from measurably huge drop in BP at 5 min of medication organization which reacted to liquid bolus in the dexmedetomidine assemble there were no unfriendly symptoms amid the examination time frame. Both groups had a similar duration of recovery from anesthesia. Dexmedetomidine before 15 minutes of extubation obtain better results. Dexmedetomidine was found to produce hypotension at 5 min of drug infusion and improved with fluid bolus; HR was stable throughout the study period.

Conclusion: Extubation quality was found to be superior in dexmedetomidine group with patients arousable and tolerating suctioning and extubation. Whereas in fentanyl group, patients were awake during extubation and had tachycardia after extubation.
\end{abstract}

Keywords: Dexmedetomidine, Fentanyl, Tracheal extubation, Bronchospasm, General anaesthesia.

\section{Introduction}

Abrupt inflated haemodynamic response during intubation and extubation noted in many cases due to release of catecholamines. ${ }^{1}$ Extubation can be associated with negative airway and hemodynamic responses. Easy extubation requires the absence of strain, patient movement, coughing, laryngospasm ${ }^{2}$ airway annoyance, intense agony following surgery, and emergence. Other drugs are used to attenuate the intubation response such as intravenous lignocaine, ${ }^{3}$ opioids such as fentanyl and remifentanil, ${ }^{4,5}$ esmolol, ${ }^{6}$ labetalol, ${ }^{7}$ intratracheal local anaesthetic instillation, ${ }^{8}$ dexmedetomidine ${ }^{9}$ which can be used during extubation also. The aim of this study was to compare the effect of sedation on airway response to endotracheal extubation with singledose dexmedetomidine and fentanyl.

\section{Materials and Methods}

A double-blind, randomized, interventional clinical trial was carried out at Saraswati Institute of Medical Sciences, from April 2019 to October 2019. Ethical approval taken from Institutional Ethical Committee. Study was carried out on fifty patients after taking written informed consent, who posted for abdominal \& lower limb surgeries under general anaesthesia, all patients were American Society of Anesthesiologists (ASA) Grades 1 and 2 of both male \& female sex, aged above 18 years, in department of anaesthesia $\&$ critical care. Patients randomization were done equally into two groups by blind approach; Group D received dexmedetomidine $0.7 \mu \mathrm{g} / \mathrm{kg}$ and Group F received fentanyl 1 $\mu \mathrm{g} / \mathrm{kg}$.
Exclusion criteria for the Patients were with upper respiratory tract infection and those required intra-operative nasogastric tube.

All patients were pre-medicated with oral alprazolam 25 mcg in the night before the surgery. On the operating room, after securing an intravenous access, injection midazolam 1.5 $\mathrm{mg}$ and injection ondansetron $4 \mathrm{mg}$ were given. Multipara monitor used to record Base line hemodynamic parameters such as HR, BP, oxygen saturation. All patients were induced with propofol $2 \mathrm{mg} / \mathrm{kg}$, fentanyl $2 \mathrm{mcg} / \mathrm{kg}$. Tracheal intubation was done using vecuronium (loading dose of 0.1 $\mathrm{mg} / \mathrm{kg}$, intermittent bolus of $0.02 \mathrm{mg} / \mathrm{kg}$ ) and anaesthesia was maintained on $\mathrm{O}_{2}: \mathrm{N}_{2} \mathrm{O}(0.5 \mathrm{~L}: 0.5 \mathrm{~L})$ and isoflurane $1 \%$ dial concentration adjusted to maintain minimum alveolar concentration to 1 . Isoflurane stopped ten minutes before expected last surgical suture, isoflurane was stopped, and equal amount of test solution $(10 \mathrm{ml})$ was given over a period of $5 \mathrm{~min}$ by infusion pump. The test solution was prepared by uninvolved anaesthesiologist. Five minutes after the infusion, the patient was reversed from muscle relaxant effect with injection neostigmine $.05 \mathrm{mg} / \mathrm{kg}$ and glycopyrrolate .01 $\mathrm{mg} / \mathrm{kg}$. Vitals taken at every 2 minutes for 10 minutes then every 5 minutes from the time of study drug administration until 15 min post extubation. Level of sedation during suction and extubation were assessed using Ramsay sedation scale (Table 1). The level of sedation during suction was assessed, and airway response under direct laryngoscopy to suction was noted by five-point scale. After 5 min interval, the level of sedation was assessed, and smoothness of extubation was noted by four-point scale (Table 2). When mean arterial BP fall more than $10 \%$ of baseline value, intravenous injection mephentermine $1 \mathrm{ml}(6 \mathrm{mg} / \mathrm{ml})$ was supplemented. Drop in 
HR more than $20 \%$ from baseline was treated with intravenous injection atropine $0.2 \mathrm{mg}$.

Statistical data analysis is done using Statistical Package for Social Sciences (SPSS Version 19, IBM Corporation, Armonk, North Castle, New York, United States). Statistical analysis was done using paired-samples $t$-test for between group comparisons. The Chi-square test was used to analyse extubation quality, sedation scores, and adverse events. $P<$ 0.05 was considered significant.

Table 1: Observer assessment sedation score

\begin{tabular}{|l|l|c|}
\hline S. No. & \multicolumn{1}{|c|}{ Observation } & Score \\
\hline 1 & $\begin{array}{l}\text { Responds readily to his/her name } \\
\text { spoken }\end{array}$ & 5 \\
\hline 2 & $\begin{array}{l}\text { Lethargic response to his/her name } \\
\text { spoken }\end{array}$ & 4 \\
\hline 3 & $\begin{array}{l}\text { Responds only after his/her name } \\
\text { called stridently }\end{array}$ & 2 \\
\hline 4 & $\begin{array}{l}\text { Responds only after mild prodding or } \\
\text { trembling }\end{array}$ & 1 \\
\hline 5 & $\begin{array}{l}\text { Does not respond to mild prodding or } \\
\text { shaking }\end{array}$ & \\
\hline
\end{tabular}

\section{Results}

From the time of test drug administration to extubation. However, dexmedetomidine produced a significant drop in heart rate when compared to fentanyl. Increase in HR in fentanyl group seen post extubation (Fig. 1).

Age, weight, gender, airway, and ASA corporeal status were analogous in both groups. The total dose of fentanyl consumed by the patients was not statistically significant (Table 4 ).

Table 4: Demographic data and total morphine consumption

\begin{tabular}{|l|c|c|c|}
\hline Parameters & Dexmedetomidine & Fentanyl & P - Value \\
\hline Age-mean (95\% CI) & $34.86(30.27-42.88)$ & $38.24(33.07-43)$ & 0.356 \\
\hline Gender (M:F) & $13: 12$ & $7: 15$ & 0.136 \\
\hline MPC* (1/2) & $11 / 13$ & $7: 17$ & 0.139 \\
\hline ASA $\left.(1 / 2)^{*}\right)$ & $19 / 2$ & $19 / 2$ & 1.2 \\
\hline Weight-mean (95\% CI) & $57.64(51.46-59.33)$ & $60.84(57.34-66.02)$ & 0.145 \\
\hline Morphine consumption Mean (95\% CI) & $6.54(6.21-7.8)$ & $6.73(6.31-7.44)$ & 0.810 \\
\hline
\end{tabular}

* Mallampatti, $\mathrm{CI}=$ Confidence interval

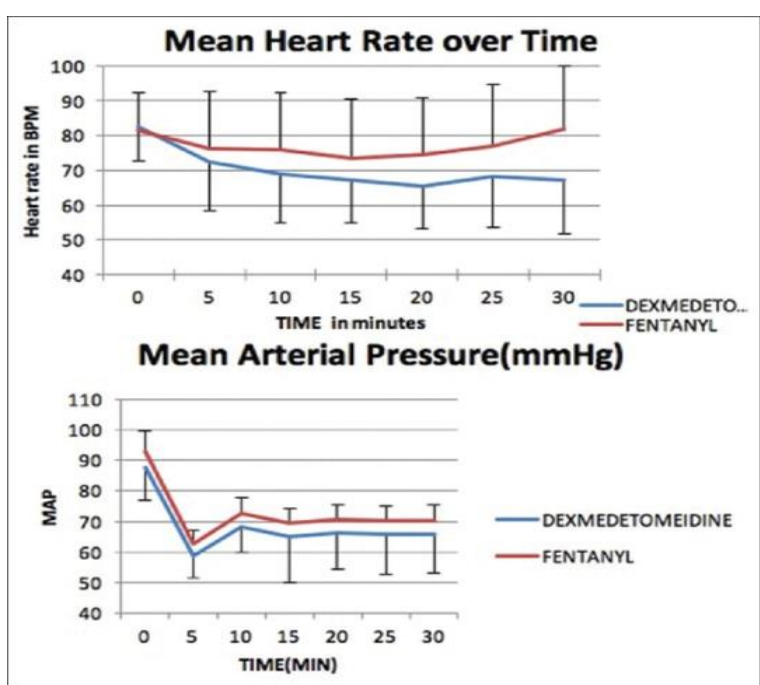

Fig. 1: Hemodynamic variations over time 
Lessening in BP was observed in both groups at $5 \mathrm{~min}$ post drug administration, which improved with fluid bolus and was maintained within $10 \%$ of baseline value throughout. (Fig. 1).

Dexmedetomidine group patients showed greater degree of sedation during suctioning of airway and extubation when compared to fentanyl. Post extubation fentanyl group patients was awake but dexmedetomidine patients were arousable. That is the reason that fentanyl group patients heart rate was increased post extubation.

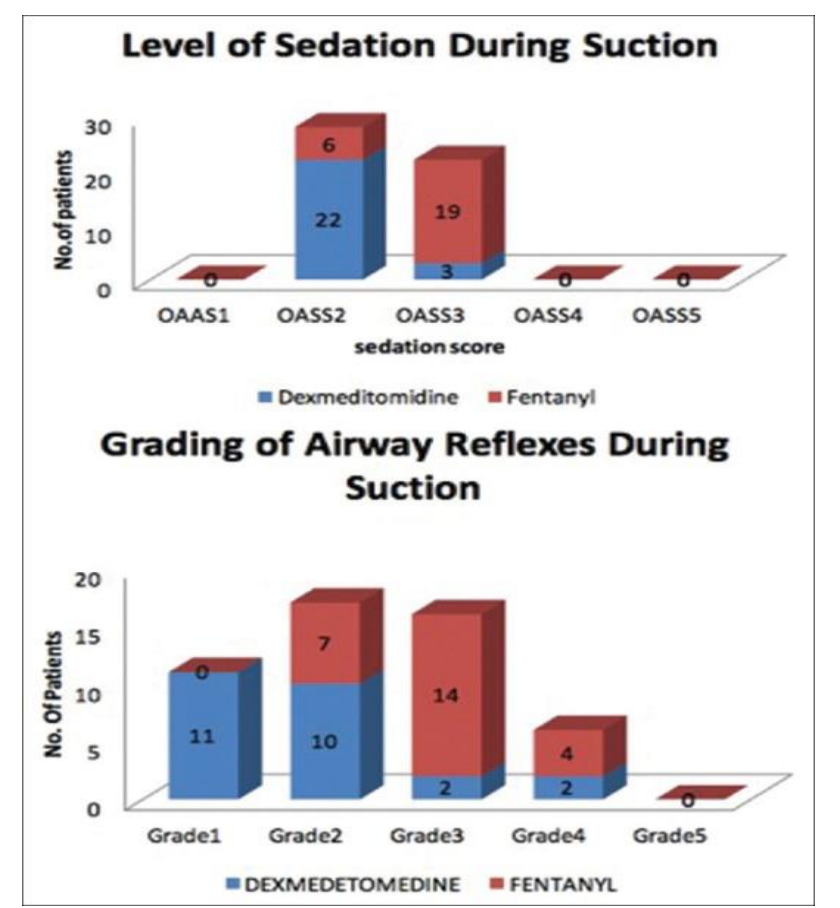

Fig. 2: Level of sedation and grading of airway reflexes during suction

Dexmedetomidine group patients in larger number tolerated laryngoscopy and suction. Infact in both the groups no breathing difficulty or related event reported (Fig. 2).

\section{Discussion}

Recouping from anesthesia regularly brings about hoisted haemodynamic parameters because of catecholamine focus following soporific with drawal which is additionally irritated by laryngeal response following extubation. Dexmedetomidine, a strong alpha-adrenoceptor agonist, diminish the thoughtful surge and noradrenergic movement accordingly neutralizing the hemodynamic variance happening at the time of extubation, ${ }^{9}$ and fentanyl is proven medication to lessen the intubation and extubation response. We recorded the impacts of dexmedetomidine and fentanyl on hemodynamic and airway reflexes during extubation.

Dexmedetomidine starts receptors in the medullary vasomotor focus, lessening norepinephrine release and decreasing central sympathetic outflow, resulting in alterations in sympathetic function and decreased HR, and BP. In our study, patients of both groups showed drop in HR and BP. On correlation between the groups, dexmedetomidine assemble demonstrated a critical drop in $\mathrm{BP}$ at 5 min interim after medication administration and enhanced with liquid boluses.

Choi et $\mathrm{al}^{10}$ did study on Ninety patients, they were randomly allocated to 1 of 3 groups: fentanyl, oxycodone, and control. Coughing responses (incidence and severity), hemodynamic responses during the recovery period, and acute postoperative pain were assessed.found that oxycodone treatment before tracheal extubation reduced cough response and was as effective as fentanyl treatment for improving extubation quality. Furthermore, single boluses of fentanyl and oxycodone showed equal effectiveness in attenuating acute postoperative pain in patients undergoing laparoscopic cholecystectomy.

Liyakhath Ali et $\mathrm{al}^{11}$ did study on One fifty patients undergoing elective surgeries under general anaesthesia were randomized into 3 equal groups. 10 minutes prior to extubation, patients received intravenous bolus infusion of $0.9 \%$ normal Saline, Fentanyl $1 \mu \mathrm{g} / \mathrm{kg}$ and Dexmedetomidine $1 \mu \mathrm{g} / \mathrm{kg}$ respectively over 10 minutes period. They found that Dexmedetomidine $1 \mu \mathrm{g} / \mathrm{kg}$ IV was most effective followed by fentanyl $1 \mu \mathrm{g} / \mathrm{kg} \mathrm{IV}$ in attenuating haemodynamic stress responses during emergence with no clinically significant differences in sedation and recovery profile. Dexmedetomidine group had smoother and best extubation quality.

D Jain et al ${ }^{12}$ conducted a double blind study on 30 patients to examine the role of Dexmedetomidine on hemodynamic changes during extubation of trachea. They found that a bolus dose of dexmedetomidine $1 \mu \mathrm{g} / \mathrm{kg}$ over 10 minutes, prior to administration of reversal provided hemodynamic stability associated with extubation \& can prove beneficial for cardiac patients where the stress response to extubation is highly undesirable.

Tarun $\mathrm{G}$ et $\mathrm{al}^{13}$ examined the effects of the alpha-2 agonist dexmedetomidine given at the end of the procedure to prevent hyperdynamic responses during extubation and to allow a comfortable and high-quality recovery. On fourty patients. They found that Without interfering in recovery time, dexmedetomidine 0.5 microg $\mathrm{kg}(-1)$ administered 5 min before the end of surgery stabilizes haemodynamics, allows easy extubation, provides a more comfortable recovery and early neurological examination following intracranial operations.

Aside from measurably huge drop in BP at $5 \mathrm{~min}$ of medication organization which reacted to liquid bolus in the dexmedetomidine assemble there were no unfriendly symptoms amid the examination time frame. Both groups had a similar duration of recovery from anesthesia. Dexmedetomidine before 15 minutes of extubation obtain better results.

\section{Conclusion}

Single-dosage dexmedetomidine $0.75 \mu \mathrm{g} / \mathrm{kg}$ given $15 \mathrm{~min}$ before extubation created better response against airway reaction to laryngoscopy. This resulted in smooth tracheal extubation without prolonging recovery in comparison to fentanyl. 


\section{Limitations}

Single dosage of dexmedetomidine and fentanyl for attenuation of hemodynamic and airway reflexes examined. A dose response study might be valuable in deciding the suitable dosage of the examination drugs. Second, five guide airway reaction toward direct laryngoscopy and airway reaction to extubation have not been approved.

\section{Funding}

Self.

\section{Conflicts of interest}

There was no conflicts of interest.

\section{References}

1. Lowrie A, Johnston PL, Fell D, Robinson SL. Cardiovascular and plasma catecholamine reactions at tracheal extubation. $\mathrm{Br}$ J Anaesth 1992;68:261-3.

2. Cranfield KA, Bromley LM. Least alveolar convergence of desflurane for tracheal extubation in profoundly anesthetized, unpremedicated youngsters. Br J Anaesth 1997;78:370-1.

3. Gefke K, Andersen LW, Friesel E. Lidocaine given intravenously as a suppressant of cough and laryngospasm regarding extubation after tonsillectomy. Acta Anaesthesiol Scand 1983;27:111-2.

4. Nishina K, Mikawa K, Maekawa N, Obara H. Fentanyl constricts cardiovascular reactions to tracheal extubation. Acta Anaesthesiol Scand 1995;39:85-9.

5. Aouad MT, Al-Alami AA, Nasr VG, Souki FG, Zbeidy RA, Siddik Sayyid SM. The impact of low-measurement remifentanil on reactions to the endotracheal tube during rising up out of general anesthesia. Anesth Analg 2009;108:1157-60.

6. Lim SH, Chin NM, Tai HY, Wong M, Lin TK. Prophylactic esmolol mixture for the control of cardiovascular reactions to extubation after intracranial surgery. Ann Acad Med Singapore 2000;29:447-51.
7. Muzzi DA, Black S, Losasso TJ, Cucchiara RF. Labetalol and esmolol in the control of hypertension after intracranial surgery. Anesth Analg 1990;70:68-71.

8. Jee D, Park SY. Lidocaine splashed down the endotracheal tube weakens the airway-circulatory reflexes by nearby anesthesia during development and extubation. Anesth Analg 2003;96:293-7.

9. Jain D, Khan R, Maroof M. Impact of dexmedetomidine on stretch reaction to extubation. Web J Anaesthesiol 2008;21:212.

10. Choi, Eun Kyung, Kwon, Nyeongkeon Park, Sang-Jin, Comparison of the effects of oxycodone versus fentanyl on airway reflex to tracheal extubation and postoperative pain during anesthesia recovery after laparoscopic cholecystectomy. Medicine: March 2018 - 97:13-0156.

11. Liyakhath Ali, Siddhram Jamgond, Jagadish M.B. Attenuation of hemodynamic stress response during emergence from general anaesthesia: A prospective randomized controlled study comparing fentanyl and dexmedetomidine. J Evol Med Dent Sci 2014;3(62):13686-96.

12. D Jain, R Khan, M Maroof. Effect of dexmedetomidine on stress response to extubation. Internet J Anesthesiol 2008:21-1.

13. Turan G, Ozgultekin A, Turan C, Dincer E, Yuksel G. Advantageous effects of dexmedetomidine on haemodynamic and recovery responses during extubation for intracranial surgery. Eur J Anaesthesiol 2008;25:816-20. 